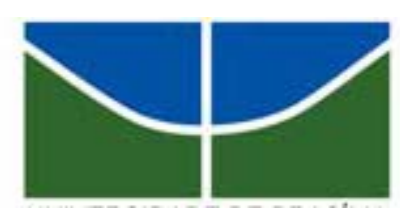

UNIVERSIDADE DE BRASÍLIA

Centro de Excelência em Turismo

Pós-graduação Lato Sensu

Curso de Especialização em Tecnologia de Alimentos

\title{
Produção do Salame e Principais Defeitos \\ (uma revisão)
}

Belimar Cleyde da Silva Borges

Dra. Ângela Patrícia Santana

(Professora orientadora) 


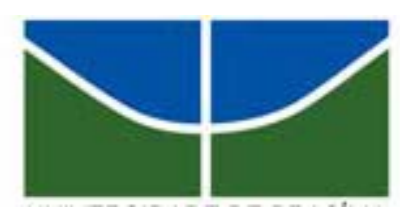

UNIVERSIDADE DE BRASÍLIA

Centro de Excelência em Turismo

Pós-graduação Lato Sensu

Curso de Especialização em Tecnologia de Alimentos

\section{Produção do Salame e Principais Defeitos \\ (uma revisão)}

Belimar Cleyde da Silva Borges

Dra. Ângela Patrícia Santana (Professora orientadora)

Monografia apresentada ao Centro de Excelência em Turismo - CET, da Universidade de Brasília - UnB, como requisito parcial à obtenção do grau de Especialista em Tecnologia de Alimentos 
Borges, Belimar Cleyde da Silva

Produção do Salame e Principais defeitos: uma revisão/ Belimar Borges. - Brasília 2007

46p. il

Monografia especialização em Tecnologia de Alimentos -Universidade de Brasília, Centro de Excelência em Tu rismo, 2007.

Orientadora: Dra. Ângela Patrícia Santana.

1.Salame 2. Produção 3. Embutidos fermentados

Produção do Salame e Principais Defeitos: uma revisão

Brasília - 2007 
UNIVERSIDADE DE BRASÍLIA

Centro de Excelência em Turismo

Pós-graduação Lato Sensu

Curso de Especialização em Tecnologia de Alimentos

\section{Belimar Cleyde da Silva Borges}

\section{Aprovado por:}

Professora orientadora: Dra. Ângela Patrícia Santana

$\overline{\text { Professor coordenador: Msc. Luiz Antônio Borgo }}$

Professora examinadora: Msc. Karla Lisboa Ramos

Brasília, janeiro de 2007. 


\section{DEDICATÓRIA}

Dedico esta monografia à minha família e especialmente à Deus que nos guardou e sustentou em todos os momentos. 


\section{AGRADECIMENTOS}

Á Universidade de Brasília, pela oportunidade de ter participado desta especialização juntamente com todos aqueles pertencentes ao corpo docente e discente. 


\section{EPÍGRAFE}

"Concedei-me, Senhor meu Deus, Uma inteligência que Vos conheça, Um zelo que vos procure, Uma ciência que Vos encontre..."

Tomás de Aquino 


\section{RESUMO}

Entende-se por salame, o produto cárneo industrializado obtido de carne suína ou suína e bovina, adicionado de toucinho, ingredientes, embutido em envoltórios naturais e/ou artificiais, curado, fermentado, maturado, defumado ou não e dessecado. Este trabalho tem por objetivo apresentar uma descrição do processo produtivo dos salames, com apresentação das principais características de qualidade e não conformidades do produto. Destacando seus principais defeitos.

Palavras-chave: Salame - Controle microbiológico - Defeitos - Embutidos Fermentados. 


\section{ABSTRACT}

It is understood for pastrami, the gotten of suína or suína and bovine meat, added industrialized cárneo product of lard, ingredients, inlaid in natural and/or artificial wraps, cured, leavend, maturate, cured or and not desiccated. This work has for objective to present a description of the productive process of the salamis., with presentation of the main characteristics of quality and not conformity of the product. Pointing its principals defects.

Key-words: Pastrami - Microbiological Control - Defects - Embuitidos Leavend. 


\section{LISTA DE ILUSTRAÇÕES}

Figura 1: Fluxograma do Processo Produtivo do Salame .8

Figura 2: Atividade de um cultivo .13

Figura 3: Reações Químicas do processo de Coloração .14

Figura 4: Processo de Coloração .15 


\section{LISTA DE QUADROS}

Quadro 1: Aditivos utilizados na produção de embutidos .................................6

Quadro 2: Tipos de Fermentação na produção do Salame...................................11

Quadro 3: Características Físico-Química ....................................................17 


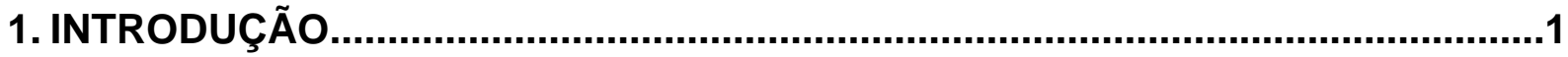

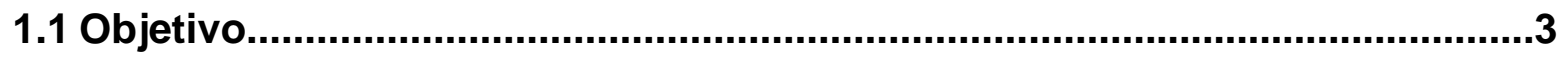

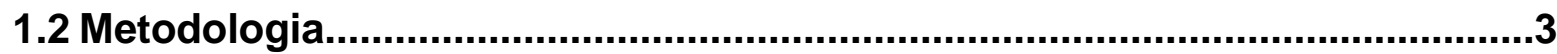

2. PRODUÇÃO DE EMBUTIDOS .....................................................................

2.1 Produtos Cárneos Embutidos Industrializados .................................. 4

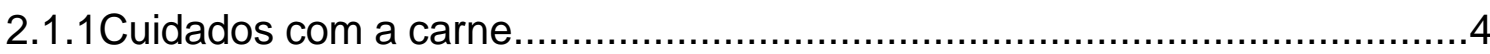

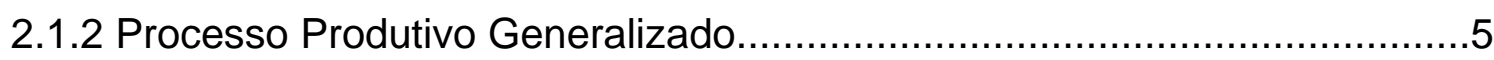

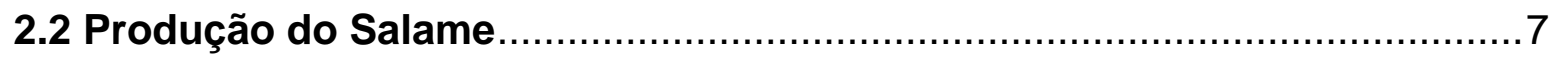

2.2.1 Processo Produtivo do Salame ..........................................................

2.2.1.1 Processo de Fermentação do Salame ......................................10

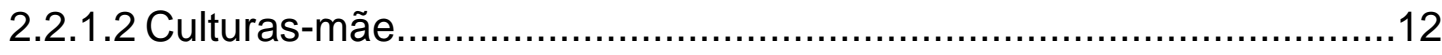

2.2.2 Características do Salame ....................................................... 13

2.2.3 Segurança e Qualidade na Produção de Salames ............................17

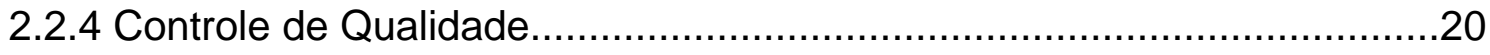




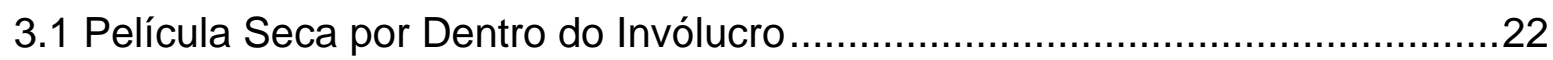

3.2 Presença de Buracos na Massa do Salame...........................................22

3.3 Salame com Camada Externa Rancificada..............................................23

3.4 Embutido com Recobrimento total de Mofos........................................23

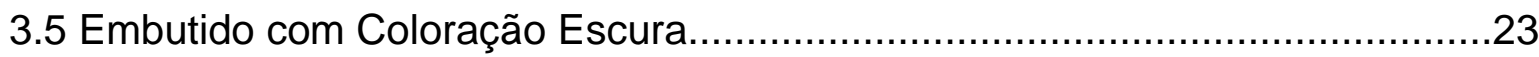

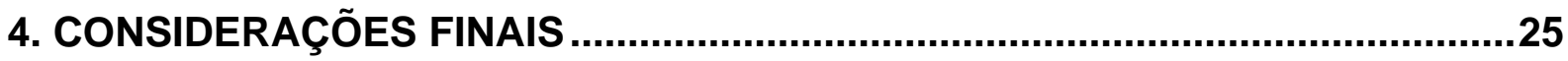

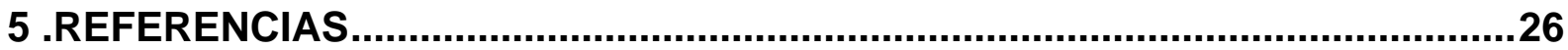

ANEXO A - PROCESSO DE DEFUMAÇÃO DO SALAME FINO.............................30

ANEXO B - INFORMAÇÕES ADICIONAIS DA PRODUÇÃO DO SALAME............32

ANEXO C - PONTOS CRÍTICOS DA FABRICAÇAO DO SALAME.........................34 


\section{INTRODUÇÃO}

A carne é um alimento com grande valor nutricional, comercial e social, mas apresenta uma limitada vida-de-prateleira. Visando a preservação da carne, foram desenvolvidos alguns procedimentos como a secagem, salga e fermentação. (VIOTT et al., 2006).

O salame, tradicional produto cárneo fermentado, teve a sua fabricação iniciada, no Brasil com a imigração italiana, no sul do país, região onde encontraram como aliado um clima propício para a produção caseira que, com o passar do tempo, deu origem as pequenas fábricas. (TERRA et al, 2004)

A produção de salames no Brasil compõe uma fatia significativa do mercado de produtos cárneos. Mudanças na busca de melhor qualidade, redução de custos e investimentos na tecnologia de produção foram percebidas pelo mercado consumidor brasileiro, que é responsável pela atual produção de 110 a 120 toneladas de salames por dia. (TERRA et al., 2004).

Entende-se por salame o produto cárneo industrializado obtido de carnes suínas e bovinas, adicionado de toicinho, ingredientes, embutido em envoltórios naturais ou artificiais, curado, fermentado, maturado, defumado ou não.

No Brasil, conforme a Instrução Normativa n²2, de 31 de julho de 2000, do Ministério da Agricultura Pecuária e Abastecimento, as características de identidade e qualidade de oito tipos de salames estão definidas, e a diferenciação entre eles está no tipo de matéria-prima, na granulometria da carne e do toicinho, com ênfase na condimentação. 
O salame é caracterizado pelas suas propriedades organolépticas, nutricionais, químicas e microbiológicas. Dois fatores básicos tornam este produto diferente dos demais embutidos: baixo teor de umidade e presença de ácido láctico, que confere um sabor característico (GRIS et al., 2002).

Os defeitos mais comuns no salame são a formação de película seca por dentro do invólucro, a presença de buracos na massa do salame, a rancificação, o recobrimento total de mofos e a coloração escura. Geralmente, ocorrem nas fases de cura, fermentação e secagem (GALLI, 1993). 


\subsection{OBJETIVO}

Este trabalho teve por objetivo discorrer a respeito da produção do salame, devido a sua importância como alimento, e apontar os principais defeitos do embutido, que têm gerado grandes perdas econômicas para o setor de embutidos crus, o qual representa um importante segmento da industrialização de carnes no Brasil.

\subsection{METODOLOGIA}

O método de abordagem utilizado, segundo procedimento técnico, foi a revisão bibliográfica, sendo um estudo qualitativo desenvolvido a partir de material já elaborado e disponível na forma de livros, artigos científicos, periódicos, revistas, disponíveis na Biblioteca Central da Universidade de Brasília e nas bases de dados: Birene, Scielo, Pro Quest, acessíveis via internet nas línguas portuguesa, inglesa e espanhola. 


\section{Produção de Embutidos}

\subsection{Produtos Cárneos Embutidos Industrializados}

O consumo de derivados de animais é muito antigo; inicialmente os produtos eram comercializados de forma natural, e posteriormente, passaram a ser processados para que formassem novos produtos até chegarem ao processo de industrialização dos seus derivados (VIVAN, BEZERRA \& FONSECA, 2002).

\subsubsection{Cuidados com a Carne}

Os animais utilizados como matéria-prima na produção precisam obrigatoriamente estar saudáveis, descansados no pré-abate e abatidos em locais limpos, com higiene. Os equipamentos e os utensílios utilizados devem também passar por processos de higienização antes e depois do uso.

Um dos primeiros processos pelo qual a carne passa é a condimentação que tem por objetivo evitar o desenvolvimento de inúmeros microrganismos e também aumentar a conservação do produto (PARDI, 1994).

Segundo Alencar (1997), a associação do sal ao açúcar e demais condimentos serve também para impressionar o paladar. Além disso, o autor também aponta que outros sais podem ser utilizados, como por exemplo o nitrato, o nitrato de sódio ou potássio, que são importantes para evitar o botulismo e demais microorganismos responsáveis pela deterioração do produto embutido.

A coloração rósea encontrada em muitos embutidos industriais é desenvolvida pela utilização do nitrato/nitrito, se manifestando pelo seu uso e duração na fermentação (ALENCAR, 1997) 


\subsubsection{Processo Produtivo Generalizado}

O processo de cura é um dos primeiros procedimentos a que a carne é submetida. Existem várias formas de realizar a cura; o que determina a escolha do processo é o tamanho da peça (CANHOS \& DIAS, S/D). O processo deve garantir a distribuição uniforme dos ingredientes no embutido a ser preparado; os erros na escolha geram defeitos que vão "desde uma coloração não uniforme, falta de estabilidade até a putrefação" (BRESSAN et al., 2002, p. 11).

Dentre os tipos de cura existente, encontramos: a cura seca para defumação posterior, a cura úmida por imersão e os métodos combinados (ALENCAR, 1997).

$\mathrm{Na}$ produção dos embutidos, os aditivos são bastante utilizados e são classificados em: conservantes, estabilizantes, condimentos, antioxidantes, aromatizantes e corantes (PARDI, 1994). Permite-se a utilização dos aditivos quando sua utilização for benéfica aos aspectos sensoriais e não trouxer riscos para o consumidor; visando a conservação e economia na produção do embutido.

O quadro a seguir aponta os principais benefícios da utilização de aditivos na produção de embutidos. 
Quadro 1: Aditivos utilizados na produção de embutidos

\begin{tabular}{|c|c|}
\hline Aditivos & \multicolumn{1}{c|}{ Benefícios } \\
\hline Conservantes & $\begin{array}{c}\text { Retardam ou impedem alterações dos alimentos provocados por } \\
\text { microrganismos ou enzimas. São encontrados comercialmente } \\
\text { com os nomes: sal de cura, cura rápida, pó húngaro, pó prague. }\end{array}$ \\
\hline Antioxidantes & $\begin{array}{c}\text { Os principais antioxidantes utilizados são os ascorbatos que } \\
\text { retardam o aparecimento de alterações oxidativas nos alimentos, } \\
\text { evitando que eles adquiram o sabor de ranço. São usados também } \\
\text { para estabilizar e unificar cor nos derivados de carne. }\end{array}$ \\
\hline Estabilizantes & $\begin{array}{c}\text { Os estabilizantes mantêm as características físicas das } \\
\text { suspensões e emulsões, evitando que os ingredientes se separem } \\
\text { com o tempo. Aumentam a capacidade de retenção e umidade da } \\
\text { carne. São utilizados freqüentemente em produtos emulsionados } \\
\text { (salsichas, patês, mortadela). }\end{array}$ \\
\hline Ascorbato & $\begin{array}{c}\text { Produtos semelhantes à vitamina C que, uma vez utilizados, } \\
\text { reduzem a incidência de formação de compostos potencialmente } \\
\text { cancerígenos, como as nitrosaminas. Além disso, o ascorbato } \\
\text { auxilia na manutenção da cor homogênea do produto cárneo } \\
\text { curado. }\end{array}$ \\
\hline Corantes & $\begin{array}{c}\text { O derivado de urucum e o açafrão são usados para melhorar a } \\
\text { coloração externa dos produtos cárneos. }\end{array}$ \\
\hline Condimentos, \\
aromatizantes \\
e especiarias
\end{tabular}

Fonte: Adaptado de Bressan et al., (2002, p. 15-16)

A operação final aplicada a alguns embutidos (produtos submetidos à cura) chama-se defumação, que tem por um dos objetivos a diferenciação de sabor. Cada produto tem seu processo ideal de defumação. 


\subsection{PRODUÇÂO DO SALAME}

No capítulo anterior apresentou-se uma breve introdução à produção dos embutidos sem a preocupação com a distinção de um produto ou outro. Nesse capítulo, o embutido estudado é o tema da presente monografia, ou seja, o Salame.

Dividido em três sub-tópicos, o capítulo em questão parte de uma análise inicial do processamento, embutimento e fermentação do salame, posteriormente faz-se um estudo de suas principais características, tais como: aroma, sabor, coloração, dentre outras e, por fim, apresenta-se uma análise dos seus principais fatores de segurança e qualidade.

\subsubsection{Processo Produtivo do Salame}

O processo produtivo do Salame compreende seis fases distintas, conforme demonstra a figura 1.

Conforme visto no capítulo anterior a primeira fase inicia-se com a escolha da matéria-prima, no caso da produção de salame a preferência deve ser das carnes de coloração avermelhada de animais mais velhos. Segundo Bobbio \& Bobbio (1992) é imprescindível que o salame seja produzido com matéria-prima maturada, com baixo valor de $\mathrm{pH}\left(5,4\right.$ e 5,8) e envelhecida durante três dias a $2^{\circ} \mathrm{C}$. Explica ainda Martins (2006, p. 10):

Se a matéria-prima tiver baixo $\mathrm{pH}$, ela apresentará uma estrutura aberta e encolhimento das fibras musculares devido a uma redução no teor de umidade. A estrutura aberta facilita a penetração dos agentes de cura e do sal acelerando o processo de cura. Além de promover uma secagem mais completa. A carne utilizada para a produção de salames deve apresentar baixo teor de umidade para minimizar o risco de multiplicação de bactérias indesejáveis. A 
gordura utilizada no processamento de salame deve estar na forma congelada e a carne resfriada.

A segunda fase do processo produtivo do salame é a trituração ou moagem da matéria-prima que é realizada em um picador de carne ou em um cutter, após a trituração dá-se à adição dos ingredientes em uma misturadeira (GRIS et al., 2002).

Figura 1: Fluxograma do Processo Produtivo do Salame

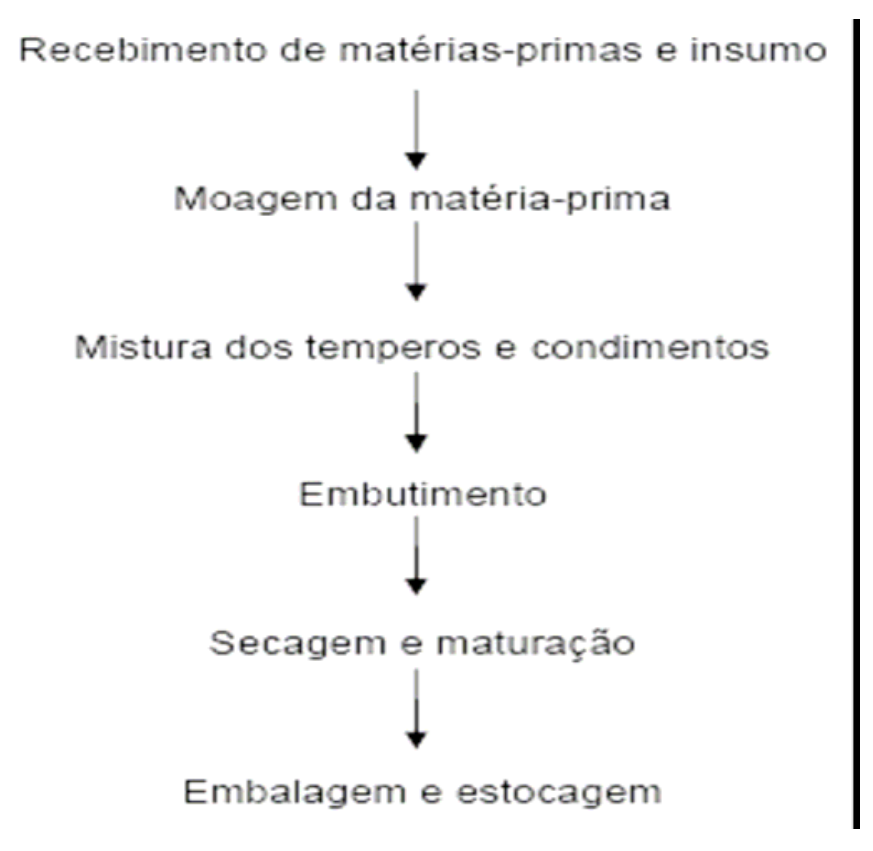

Fonte: TERRA (2003)

O próximo passo da preparação do salame é misturar e modelar a massa em forma redonda para a total remoção do ar. Segundo Martins (2006, p. 11) o processo de embutimento consiste em: "introduzir a massa já preparada na tripa previamente selecionada e disposta para este fim em equipamentos chamados embutideiras ou embutidoras." 
Existem dois tipos de embutideiras: pistão (descontínua) e a vácuo (contínua). Conforme define Martins (2006, p.11):

As embutideiras podem ser descontínuas (pistão) ou contínuas (a vácuo). As de pistão são compostas por um cilindro onde se desloca um pistão sobre o qual se dispõe a massa a ser embutida. Quando o pistão sobe pelo cilindro, direciona a massa a um orifício conhecido como pico. As embutideiras à vácuo são compostas por um grande funil coletor no qual se dispõe uma vareta que mexe a massa, evitando sua condensação. A massa é impelida por pressão até o orifício de saída onde está a tripa. Estes equipamentos têm capacidade média de produção entre 6 e 9 ton/h.

A utilização de tripas artificiais se dá por não apresentarem problemas de higiene, por favorecerem o embutimento padronizado e não dificultarem a manipulação do material bem como seu armazenamento.

As tripas mais utilizadas são as de colágeno, celulose ou de materiais plásticos que podem ser o poliéster, a poliamida, o polietileno e o cloreto de polivinila (REIS \& SOARES, 1998).

O penúltimo processo produtivo do salame é a secagem e maturação, que é o processo mais delicado devido à massa estar ainda fresca e com água, permitindo a proliferação de microrganismos (TERRA, 2003). A maturação, para obter sucesso, segundo Redetec (2006, p. 11), precisa ser feita da seguinte maneira:

A maturação é feita à temperatura entre +18 e $+/-20^{\circ} \mathrm{C}$ e a umidade relativa no primeiro dia deve estar em torno de $95 \%$. A umidade deve ser reduzida durante três a quatros dias para $85 \%$. A velocidade do ar não pode ser mais do que 0,1 ou $0,2 \mathrm{~m} / \mathrm{s}$. Depois de curados, os salames são colocados para maturação adicional e secagem para estabilização da cor, desenvolvimento do aroma e finalização do processo de preparo para a estocagem do produto. A secagem é feita a temperaturas entre 12 e $15^{\circ} \mathrm{C}$ e numa umidade relativa de 70 
a $75 \%$ com velocidade do ar menor que $0,1 \mathrm{~m} / \mathrm{s}$. Quando o salame perde de 25 a $30 \%$ de seu peso, este já pode ser embalado e comercializado.

O último processo é o da estocagem e embalagem. O salame deve ser, portanto, embalado em materiais que o protejam contra a contaminação.

\subsubsection{Processo de Fermentação do Salame}

O processo de fermentação do salame é o mesmo processo de defumação já explicado no capítulo anterior, mas pretende-se aqui entrar em detalhes no que tange esse processo na fabricação do Salame.

Existem dois tipos de fermentação rápida para a produção do salame: a tradicional e a Sweating Fermentation, além dessas duas ainda tem-se a fermentação por defumação úmida, a fermentação em salmora, a fermentação sobpressão e a fermentação à vácuo (MARTINS, 2006).

O quadro a seguir apresenta detalhadamente cada um dos tipos de fermentação que podemos encontrar no processo de produção do salame. 
Quadro 2: Tipos de Fermentação na produção do Salame

\begin{tabular}{|c|c|}
\hline $\begin{array}{c}\text { Tipo de } \\
\text { Fermentação }\end{array}$ & Processo de Fermentação \\
\hline $\begin{array}{c}\text { Fermentação } \\
\text { rápida } \\
\text { tradicional }\end{array}$ & $\begin{array}{l}\text { Os salames são mantidos durante } 12-14 \mathrm{~h} \text { a temperatura de } 24- \\
26^{\circ} \mathrm{C} \text {, na tentativa de aumentar a temperatura da massa } \\
\text { rapidamente. Feito isso, a temperatura é reduzida para a faixa de } \\
18-20^{\circ} \text { de modo a finalizar a fermentação, formar cor padrão e } \\
\text { conferir liga a massa. Durante a desidratação, a velocidade do ar } \\
\text { não pode exceder a } 0,1-0,2 \mathrm{~m} / \mathrm{s} \text {, caso contrário o embutido começa } \\
\text { a apresentar mela em sua superfície, ocasionando perda de } \\
\text { produção. }\end{array}$ \\
\hline $\begin{array}{l}\text { Fermentação } \\
\text { rápida } \\
\text { (Sweating } \\
\text { Fermentation) }\end{array}$ & $\begin{array}{l}\text { Neste tipo de fermentação são utilizadas temperaturas mais altas } \\
\left(25-28^{\circ} \mathrm{C}\right) \text {, fazendo-se necessária maiores concentrações de sal } \\
\text { nos primeiros estágios, dada a perda excessiva de água e sal. É } \\
\text { comum a formação de mela na superfície do produto, recomenda- } \\
\text { se à lavagem e secagem ao ar do embutido antes do processo de } \\
\text { defumação. }\end{array}$ \\
\hline $\begin{array}{l}\text { Fermentação } \\
\text { por } \\
\text { defumação } \\
\text { úmida }\end{array}$ & $\begin{array}{l}\text { Neste processo, a fermentação, a defumação e a secagem do } \\
\text { salame ocorrem em uma única etapa em temperaturas altas } \\
\text { constantes. Assim como na fermentação rápida, os produtos } \\
\text { produzidos deste modo apresentam diferenças de cor, baixa } \\
\text { estabilidade de cor, diferenças de cheiro e sabor. }\end{array}$ \\
\hline $\begin{array}{l}\text { Fermentação } \\
\text { em salmoura }\end{array}$ & $\begin{array}{c}\text { É utilizada uma salmoura de } 6-8 \% \text {, podendo conter ascorbato de } \\
\text { sódio ou não, em temperaturas mais altas }\left(18-22^{\circ} \mathrm{C}\right) \text {, onde ocorre a } \\
\text { liga da massa em 3-5 dias e a cor é aceitável ou em temperaturas } \\
\text { baixas }\left(8^{\circ} \mathrm{C}\right) .\end{array}$ \\
\hline $\begin{array}{l}\text { Fermentação } \\
\text { sob pressão }\end{array}$ & $\begin{array}{c}\text { São utilizadas formas de pressão de plástico ou metal. Os } \\
\text { embutidos são colocados nas formas que são fechadas e } \\
\text { pressionadas. Neste processo, o produto é mantido em } \\
\text { temperaturas entre } 20-22^{\circ} \mathrm{C} \text {. }\end{array}$ \\
\hline $\begin{array}{l}\text { Fermentação } \\
\text { a vácuo }\end{array}$ & $\begin{array}{c}\text { Utiliza-se um recipiente a vácuo, no qual pressões reduzidas (0,5 } \\
\text { atm) possam ser produzidas e mantidas. Após serem colocados } \\
\text { numa câmara, os salames são expostos a pressão de } 2 \text { atm por } \\
\text { algum tempo e após o restabelecimento da pressão normal, a } \\
\text { pressão é reduzida para } 0,3 \text { atm . Este processo se repete até que } \\
\text { a pressão se normalize a } 0,5 \text { atm. }\end{array}$ \\
\hline
\end{tabular}

Fonte: adaptado de MARTINS (2006) 


\subsubsection{Culturas-mãe}

As culturas-mãe vêm sendo utilizadas em salames e têm por objetivo influenciar o "processo de maturação e aroma durante o processamento de salames, podendo ser utilizadas tanto puras como combinadas" (MARTINS, 2006, p. 12). Ou seja, a combinação de culturas de Micrococcus e Lactobacillus aceleram a formação da cor, influenciam na consistência do produto pela redução do pH (GRIS et al., 2002).

Segundo Carione et al (2001), já foram testados os seguintes microrganismos: Pediococcus cerevisae; Lactobacillus plantarum; L. acidophilus e outros; Streptococcus lactis; S. cremoris; Micrococcus aurenticus; M. lactis. Para produção de culturas, foram utilizados os seguintes microrganismos: Pediococcus cerevisae; Lactobacillus plantarum; Streptococcus lactis; Micrococcus aurenticus; M. lactis.

As adições destas culturas aos salames podem ser feitas de forma pura ou misturadas, desde que sejam seguidos alguns princípios, conforme aponta o estudo de Martins (2006, p. 12-13):

a) Seleção: Podem ser cultivos já estabelecidos ou seleciona-se após provar numerosas estirpes que deve ser estável e o rendimento e velocidade a que se reproduzem as mudanças devem ser estáveis. b) Manutenção: Uma vez obtido um cultivo satisfatório, há que mantê-lo puro e ativo e pode ser através de transferências periódicas. Os cultivos de reserva podem ser através de liofilização ou congelamento em nitrogênio líquido.

c) Preparação de cultivos: Feito com a cultura estoque mantida conservada ou com culturas isoladas na etapa seletiva: cultivos bacterianos, de leveduras, mofos e mistos. 
A figura a seguir apresenta um exemplo da atividade de um cultivo apontando os microorganismos e seus produtos finais.

Figura 2: Atividade de um cultivo

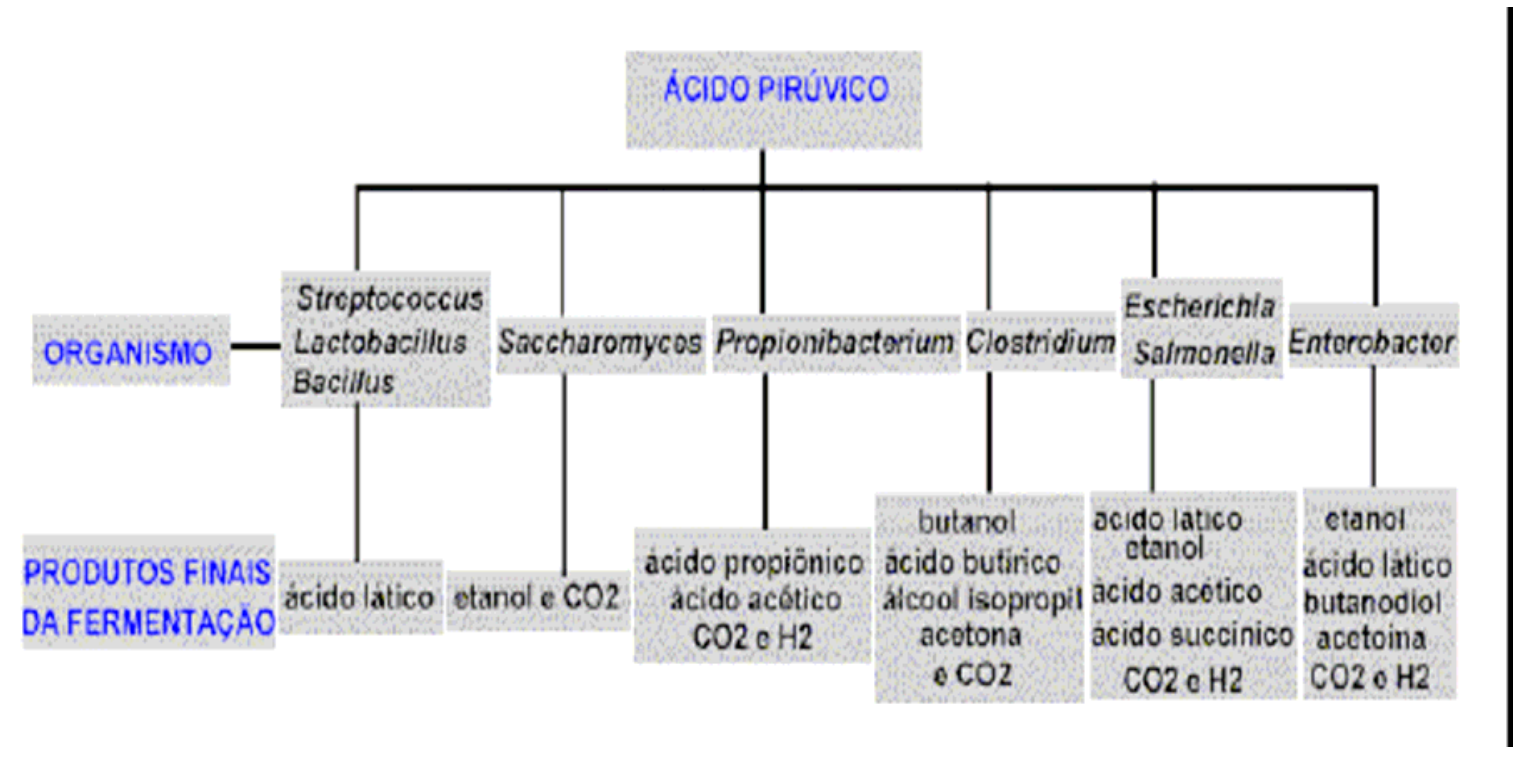

Fonte: MARTINS (2006, p. 12)

\subsubsection{Características do Salame}

As principais características do salame giram em torno de sua coloração, aroma e sabor. Assim, este tópico tem por objetivo estudar essas e outras características típicas desse embutido.

A coloração do salame é uma combinação do óxido nitroso derivado do salitre ou sal de cura com o pigmento mioglobina do músculo. Segundo Martins (2006, p. 13): "O complexo mioglobina-óxido nitroso é o responsável pela coloração vermelha do salame. A instabilidade da cor de cura pode ser causada pela produção de determinados peróxidos por lactobacilos, micrococcus, formas esporogênicas 
aeróbias ou coliformes". A figura 6 apresenta essas reações que envolvem o processo de coloração.

Figura 3: Reações Químicas do processo de Coloração

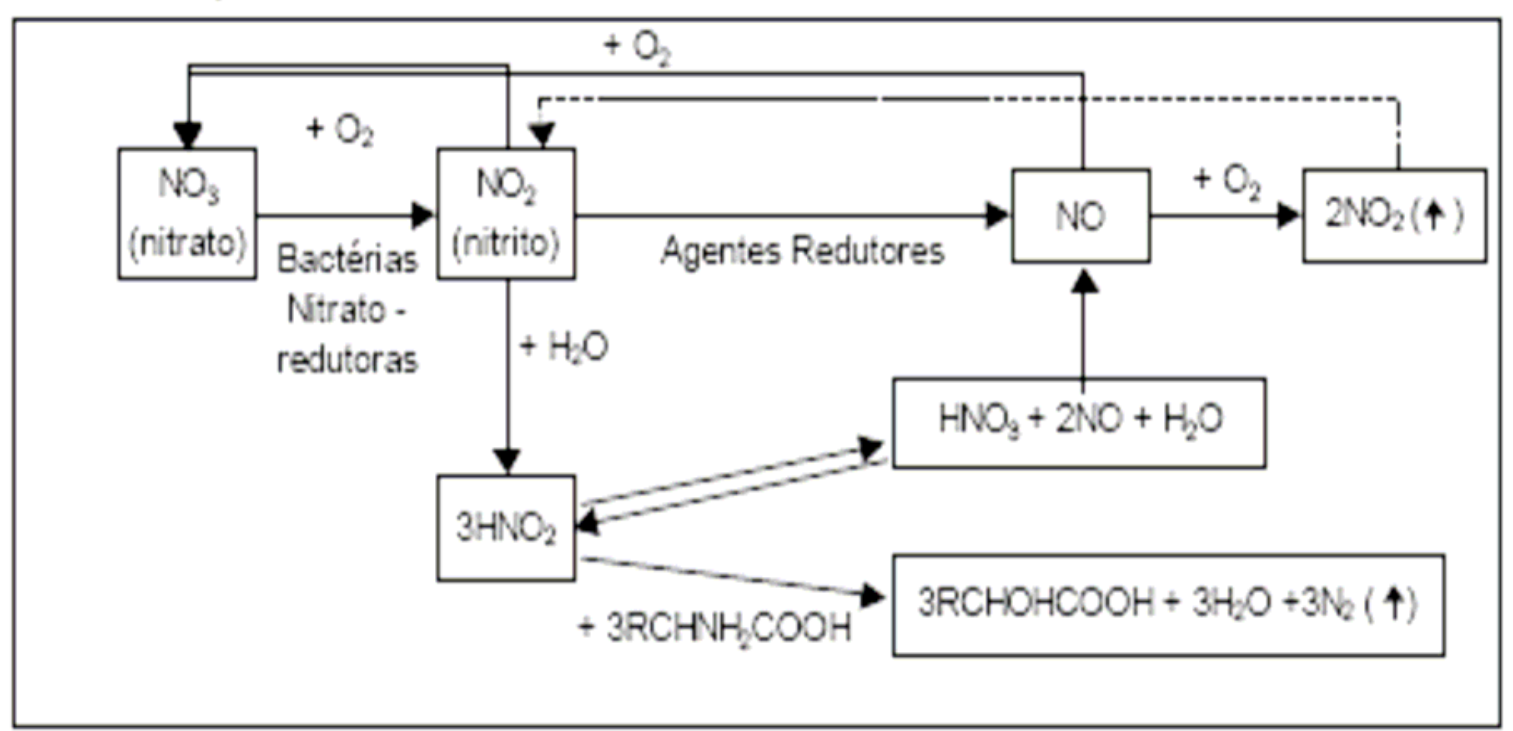

Fonte: TOWSEND \& BARD (1971)

Conforme se verificou, os aditivos são responsáveis pela coloração e também por outras características dos produtos embutidos; portanto, a cor do salame está associada à conformação química e concentração dos pigmentos heme, mais especificamente da mioglobina, composta por uma cadeia polipeptídica denominada globina, acoplada a um grupo prostético, denominado heme, composto por um átomo de ferro e um anel porfirínico (CLYDESDALE \& FRANCIS, 1976).

A coloração do salame pode variar dependendo da quantidade relativa de três formas de mioglobina, podendo ser: vermelha púrpura, vermelha brilhante e marrom. Todo esse processo é melhor visualizado na figura 7, mas cabe aqui apontar a explicação do processo apontada por Faria et al (2001, p. 17): 
As reações entre as três formas de mioglobina são reversíveis e estão num estado de equilíbrio dinâmico, com uma constante interconversão entre elas. A mioglobina reduzida na presença de oxigênio é convertida a oximioglobina, reação favorecida por altas pressões de oxigênio (40 torr). Sob pressões reduzidas de oxigênio (1 a 1,4 torr) ocorre a oxidação do ferro heme ( $\mathrm{Fe}^{2+}$ ) ao seu estado férrico $\left(\mathrm{Fe}^{3+}\right) .(\ldots)$ A metamioglobina pode ser reduzida a mioglobina através da ação de enzimas redutoras, NADH dependentes, fenômeno denominado MRA (metamyoglobin-reducing activity). O cofator enzimático NADH é obtido do processo de oxidação enzimática de substratos endógenos como a glicose, ainda presente em carnes frescas. Assim que os substratos oxidáveis são suprimidos, o poder redutor dos tecidos é perdido e o ferro do heme pigmento é oxidado a MetMb.

Figura 4: Processo de Coloração

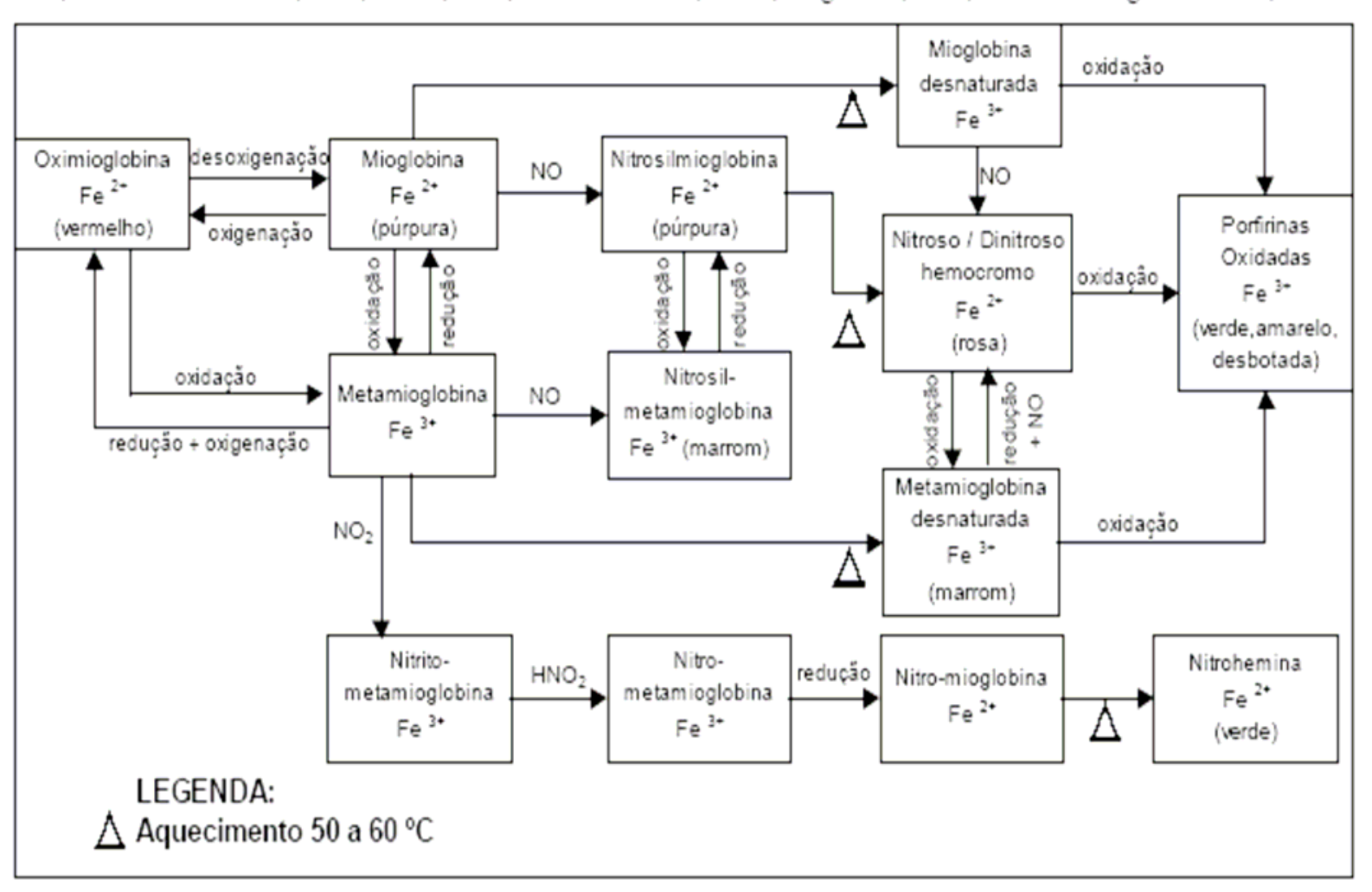

Fonte: FARIA et al (2001, p. 17) 
O aroma levemente ácido dos salames é causado pela acidificação, assim como o sabor amargo é causado pela presença de ácido láctico. Conforme explica Terra (2003):

\begin{abstract}
Durante a modificação química e microbiológica das proteínas, lipídeos e carboidratos, várias substâncias formadas influenciam no sabor e aroma do produto final. Quando fermentados em temperaturas muito altas, os salames apresentam um sabor e aroma forte cáustico devido à multiplicação de bactérias do grupo Mesentericus subtilis, podendo ser causada também pela quebra de aminoácidos por lactobacilos. O sabor amargo é conseqüência da defumação com fumaça úmida ou fungada ou de madeira tratada com substâncias químicas. Salames que apresentam sabor de ranço foram expostos a luz e ao calor ou sofreram ação de microrganismos que hidrolisam a gordura.
\end{abstract}

Outra característica do salame é a sua textura que envolve um processo físico-químico, ou seja, são interações que ocorrem entre partículas de carne, gordura e proteínas liberadas durante o processo de trituração. "À medida que o pH vai baixando $(<5,3)$, o componente extraído da proteína atua na ligação entre as partículas de carne e gordura por meio da modificação de sua forma sol para gel" (MARTINS, 2006, p. 13).

Para finalizar o presente tópico, o quadro a seguir apresenta as características físico-químicas que devem ser encontradas nos salames. 
Quadro 3: Características Físico-químicas

\begin{tabular}{|r|l|}
\hline \multicolumn{1}{|c|}{ Características } & \multicolumn{1}{|c|}{ Quantidade } \\
\hline Atividade de água & Aw (máx.): 0,92 \\
\hline Umidade & (máx.): 40\% \\
\hline Gordura & (máx.): 35\% \\
\hline Proteína & (mín.): $20 \%$ \\
\hline Carboidratos & (máx.): 1,5\% \\
\hline
\end{tabular}

Fonte: adaptado de MARTINS (2006)

\subsubsection{Segurança e Qualidade na Produção de Salames}

Como se verificou no decorrer deste trabalho, os microrganismos exercem papel fundamental na preparação do salame, porém eles precisam de condições adequadas para crescerem e são estas condições, que determinam a qualidade de vida microbiológica e devem ser analisadas em todos seus aspectos (EVANGELISTA, 2001).

A qualidade do substrato, por sua vez, é a principal condição para a presença do microrganismo, conforme aponta Evangelista (2001, p. 33):

Os requerimentos calóricos, plásticos e reguladores, sob as formas simples e complexas em que se encontram nos alimentos, não podem ser aproveitadas pelos microrganismos, de modo generalizado. É necessário que esses microrganismos possuam características especiais, como, por exemplo, a presença de enzimas, para a hidrólise prévia dos nutrientes a serem consumidos. O fator condição do substrato está, pois, intimamente ligado à existência e proliferação microrgânica. 
A contaminação do embutido pode ocorrer em qualquer fase da sua produção e esta contaminação pode ser por agentes físicos, substâncias tóxicas, microrganismos infecciosos ou toxigênicos (EVANGELISTA, 2001).

A preocupação com a segurança dos produtos se dá pela alta incidência de doenças transmitidas pelos alimentos. O salame, por sua vez, esta sujeito a contaminação por várias fontes: inicialmente, pelo próprio animal, posteriormente pela água, pelas instalações industriais, equipamentos mal higienizados dentre outras (EVANGELISTA, 2001). Daí a necessidade de se monitorar todo o processo de produção do salame.

As bactérias lácticas, como já foi visto, constituem um grupo de microorganismos amplamente distribuídos nos salames, bem como em outros alimentos. Essas bactérias são responsáveis por uma variedade de compostos antimicrobianos, incluindo: ácidos, diacetil, peróxido de hidrogênio, dióxido de carbono, álcool, aldeído e bacteriocina (BROMBERG et al., 2006). Porém, cada composto citado pode acarretar no crescimento de bactérias deterioradoras e patogênicas. Conforme aponta Shillinger \& Lücke apud Bromberg et al. (2006, p.135):

(...) bactérias lácticas originalmente isoladas de carnes e produtos cárneos são os microorganismos mais indicados para serem utilizados na intensificação da segurança microbiológica destes alimentos. (...) estas bactérias são adaptadas às condições das carnes e devem, desta forma, ser mais competitivas comparativamente às bactérias lácticas provenientes de outras fontes. A nisina, bacteriocina produzida por Lactococcus lactis subsp. lactis, apresenta uma baixa eficácia na biopreservação de carnes devido à sua baixa solubilidade, distribuição não uniforme e baixa estabilidade. Além disso, a dose requerida é considerada antieconômica, excedendo a ingestão diária aceitável para um consumo de $100 \mathrm{~g}$ de carne por dia para uma pessoa de $60 \mathrm{~kg}$. 
Conforme se sabe, vários tipos de salames são comercializados e produzidos no Brasil, os quais apresentam variação em sua composição, calibre, grau de moagem dos ingredientes e condimentos adicionados, defumação ou não e período de maturação. O tipo mais comum de salame comercializado no Brasil é o italiano, caracterizando-se pela sua moagem média (6 a $9 \mathrm{~mm}$ ), é curado, fermentado, apresentando tempo de maturação de 25 a 50 dias e é dessecado (GLORIA et al., 2006).

A histamina faz parte de um grupo de substâncias denominadas aminas bioativas, as quais desempenham papel importante no metabolismo celular. Entretanto, podem causar efeitos tóxicos quando presentes nos alimentos em concentrações elevadas ou quando a atividade das enzimas metabolizadoras dessas substâncias no homem for deficiente por problemas genéticos ou inibida por agentes farmacológicos. As intoxicações alimentares mais freqüentes causadas por aminas envolvem a histamina, a tiramina e a feniletilamina. Outras aminas, as biogênicas, podem ser formadas por microrganismos que possuem atividade aminoácido-descarboxilase, sejam estes adicionados intencionalmente (cultura iniciadora), ou não (microbiota contaminante) (GLORIA et al., 2006).

Tendo em vista os processos de fermentação e maturação a que os salames são submetidos, esses se tornam susceptíveis à formação de aminas. De fato, a presença de tiramina e histamina em teores elevados tem sido relatada em produtos cárneos fermentados ou maturados de vários países (GLORIA et al, 2006).

O estudo recente de Gloria et al (2006) é preocupante pelo fato dos teores de tiramina encontrados em todas as marcas serem potencialmente capazes de causar intoxicação. Amostras de duas marcas poderiam causar também intoxicação por 
histamina e por feniletilamina. Nenhuma das marcas analisadas estava em conformidade com a legislação brasileira no que diz respeito a, pelo menos, uma das características físico-químicas de identidade e qualidade. $\mathrm{O}$ autor sugere a inclusão de tiramina como característica para a garantia da qualidade de salames tipo italiano e que as indústrias envidem esforços para minimizar os teores de aminas biogênicas nos salames tipo italiano e se adequem à legislação vigente.

O desenvolvimento de fungos filamentosos na superfície dos salames durante a maturação é considerado um fator de qualidade que deve complementar mudanças bioquímicas envolvidas na maturação do produto. Muitos destes fungos podem, no entanto, ocasionar alterações de cor e sabor e ataque ao envoltório, como também representar um problema de saúde pública pelas toxinas que podem produzir (CASTRO, 2000).

Uma perfeita cobertura de fungos sobre a superfície de salames auxilia numa perda de umidade mais homogênea, de forma lenta e progressiva, atuando na diminuição da formação de crosta na superfície dos embutidos.

\subsubsection{Controle de Qualidade}

A higienização em uma indústria de alimentos merece um destaque especial. Casos de alterações de produtos alimentares e de contaminações inaceitáveis, envolvendo custos, têm sido atribuídos a falhas ou insuficiência desses procedimentos (THRUN, 2003).

Ferramentas de gestão da qualidade têm sido criadas e implementadas para garantir um alimento seguro, além de proporcionar diminuição de custos, redução de perdas e otimização da produção (FURTINI; ABREU, 2005). As Boas Práticas de 
Fabricação (BPF) e o Sistema APPCC (Análise de Perigos e Pontos Críticos de Controle) são ferramentas amplamente recomendadas por órgãos de fiscalização tais como a Agência Nacional de Vigilância Nacional - ANVISA e Ministério da Agricultura, Pecuária e Abastecimento - MAPA, e utilizada em toda cadeia produtiva de alimentos. Recentemente, a Associação Brasileira de Normas Técnicas - ABNT disponibilizou o Guia de aplicação da ABNT NBR ISO 22000:2006 baseada nos princípios do APPCC para promover a eficácia e a eficiência de um sistema de gestão de segurança de alimentos. 


\section{Principais defeitos do salame}

Este capítulo tem por objetivo apontar os principais defeitos do salame. De acordo com Galli (1993), os maiores problemas ocorrem nas fases de fermentação e secagem, causando um desenvolvimento insuficiente da formação de cor, das propriedades de liga e estabilização insatisfatória. Com o que concorda De TONI et al (1994), destacando defeitos como fermentação ácida (quando o pH é menor que 5,4); massa não gelificada caracterizando falta de liga da massa que permanece frouxa e esfarelada; fermentação gasosa, que se caracteriza pela presença de buracos e alterações de cor do produto.

Terra et al (2004) chama a atenção para a importância das matérias-primas utilizadas na produção do salame. Ao que Takahashi (1993) corrobora, citando que as especiarias naturais podem introduzir contaminação bacteriana no produto cárneo, podendo deteriorá-lo ou pelo menos encurtar sua vida-de-prateleira.

\subsection{Película seca por dentro do invólucro}

Segundo Galli (1993), erros na secagem podem produzir uma película exterior seca abaixo do invólucro. Assim, a umidade das partes internas não pode sair e haverá um desenvolvimento microbiano acompanhado de mudanças de cor, cheiro, consistência e sabor.

\subsection{Presença de buracos na massa do salame}

Uma das possíveis causas para a presença de buracos na massa do salame é a ação de bactérias lácticas heterofermentativas não desejadas na fase fermentativa do salame. (TERRA et al., 2004) 


\subsection{Salame com a camada externa rancificada}

Como relata Terra et al (2004) a rancificação superficial das peças é resultado de uma estocagem com temperatura, umidade e iluminação inadequadas. A comercialização do salame na forma fatiada, em embalagens a vácuo tradicionais ou tipo skin packaging, requer barreiras ao oxigênio e à luz ainda maiores. Tal fato é conseqüência do aumento da área superficial do produto exposta ao meio ambiente, resultante do processo de fatiamento, o que agrava os problemas de descoloração, rancificação e deterioração microbiológica. (MARCHES et al., 2006)

\subsection{Embutido com recobrimento total de mofos}

O desenvolvimento de fungos filamentosos na superfície dos salames durante a maturação é considerado um fator de qualidade que deve complementar mudanças bioquímicas envolvidas na maturação do produto. Muitos destes fungos podem, no entanto, ocasionar alterações de cor e sabor e o ataque ao envoltório, como também representar um problema de saúde pública pelas toxinas que podem produzir. (CASTRO et al., 2000 )

\subsection{Embutido com coloração escura}

Este fato indesejável poderá ocorrer tanto em conseqüência da adição exagerada de sal de cura (erro na pesagem), como da utilização de sal de cura mal elaborado e por isso não homogêneo, uso de fixador de cor em dose insuficiente ou

parcialmente oxidada e presença de bactérias lácticas heterofermentativas. (TERRA et al., 2004). 
De acordo com (Roça 1998), vários eventos afetam a estabilidade da cor de produtos cárneos curados. Uma coloração escura pode ser observada em produtos que sofrem desidratação superficial, o que promove a concentração dos pigmentos e ao mesmo tempo altera as propriedades ópticas das fibras musculares. Pode-se, também, verificar o escurecimento devido à adição excessiva de nitrito, ao mesmo tempo em que a má distribuição da salmoura pode promover o desenvolvimento de cor deficiente, maior deteriorização microbiológica de pontos que não contenham a solução de cura e a formação de áreas esverdeadas ou ácidas. 


\section{CONSIDERAÇÕES FINAIS}

O presente trabalho visou contribuir com o estudo do processamento de produtos cárneos embutidos, mais especificamente o salame, fazendo uma revisão bibliográfica sobre os principais defeitos apresentados, com o intuito de minimizar as perdas decorrentes de desvios no processo de cura, fermentação, secagem e armazenamento dos produtos.

Como toda produção de alimentos, a produção de salame necessita ser acompanhada por profissional especializado na área de alimentos para desempenhar atividades como elaboração da formulação e controle de processo.

Os produtos devem atender aos Padrões de Identidade e Qualidade e as indústrias produtoras devem atender as exigências do Ministério da Agricultura, Pecuária e Abastecimento. 


\section{REFERÊNCIAS BIBLIOGRÁFICAS}

ALENCAR, N. Embutidos e defumados de carne suína. Belo Horizonte. SENAR AR/MG, 1997.

BOBBIO, P. A ; BOBBIO, F. O., Química do Processamento de Alimentos, Editora Varela, 2ª Edição, 1992.

BRESSAN, M. C.. Produtos cárneos e defumados mais sabor e maior valor agregado. Departamento de Zootecnica da UFLA, 2002.

BROMBERG, R.; MORENO, I.; DELBONI, R. R.. Característica da Bacteriocina produzida por Lactococcus Lactis ssp hordniae ctc 484 e seu efeito sobre Listeria monocytogenes em Carne bovina. Ciênc. Tecnol. Aliment., Campinas, 26(1): 135-144, jan.-mar. 2006.

CANHOS, D. A. L. E.; DIAS, E. L.. Tecnologia de carne bovina e produtos derivados. São Paulo. Sec. Da Indústria, comércio, ciência e tecnologia. [s.d.].

CARIONI, F. O.; PORTO, A. C. S.; PADILHA, J. C. F.; SANT'ANNA, E. S., Uso de Culturas Iniciadoras para Elaboração de um Embutido a Base de Carne de Pato. Ciênc. Tecnol. Aliment. vol. 21 n.3 Campinas Set/Dez. 2001.

CASTRO, L. C.. Efeito do uso da cepa starter de Penicillium nalgiovense na qualidade de salames. Ciênc. Tecnol. Aliment. vol.20 n.1 Campinas Apr. 2000.

CLYDESDALE, F. M.; FRANCIS, F. J. PIGMENTS. In: Fennema, O, R. ed. Principles of Food Science. Part I: Food Chemistry. 11 a edição. New York: Marcel Dekker, Inc., 1976. v. 4, p.393-402. 
De TONI, C.H.; De TONI, C. Jr.; SANTANA, E. S.; OGLIARI, P.J., Uso de bactérias lácticas e seus efeitos nas variações do pH de nitrito durante a maturação do salame tipo italiano, SBCTA, 28 (1):1-9, janeiro/junho de 1994.

EVANGELISTA, J., Tecnologia de Alimentos, Editora Atheneu, 2001.

FARIA, J. A. F., FELíclo, P. E., NEVES, M. A., ROMANO, M. A. - Formação e Estabilidade da Cor de Produtos Cárneos Curados Revisão - Revista TeC Carnes - Campinas, SP, v.3, n.2, p.16-22, 2001.

FURTINI, L.L.R., ABREU, L.R., Comunicação utilização de APPCC na indústria de alimentos, Lavras, 2006, Ciência agrotec., v.30, n2, p.358-363.

GALLI, F., Os embutidos - Como fabricá-los, Revista Nacional da Carne, Ed 194, Abril de 1993.

GLORIA, M. B. A; CACCIOPPOLI, J.; CUSTODIO, F. B.; VIEIRA, S. M.. Aminas bioativas e características físico-química de salame tipo italiano. Arq. Bras. Med. Vet. Zootec., v.58, n.4, p.648-657, 2006.

GRIS, E. F., BORTOLUZZI, R.. Produtos Fermentados, Revista Nacional da Carne, Ed. 308, Outubro de 2002. Disponível em <http://www.dipemar.com.br/CARNE/308/materia_arttec_carne.htm >. Acesso em: 31 jan 2006.

MARCHES, C. M.; CICHOSKI, A. J.; ZANOELO, E. F.; DARIVA, C., Influência das Condições de Armazenamento sobre os Pigmentos Cárneos e a Cor do Salame Italiano Fatiado, Ciênc. e Tecnol. Aliment. Vol.26 n.3 Campinas jul/sep. 2006. 
MARTINS, R. Dossie técnico: Produção de Embutidos Crus-Curados (salame). REDETEC: julho, 2006.

SCHMELZER-NAGEL, W.; AMBIEL, C. A cor e a cura de carnes e derivados, Rio de Janeiro: CNTPA do SENAI, 1998.

PARDI, M. C. Ciência, Higiene e Tecnologia de carne. Goiânia. Ed. Universitária, EDUFF, 1994.

REIS, A. G. B. \& SOARES, G. J. D., Salame Colonial processado com carne suína e ovina, Revista Brasileira de Agrociência, Maio-Agosto, 1998.

TAKAHASHI, G., Ingredientes e suas funções na fabricação de produtos cárneos, Revista Nacional da Carne, Ed. 199 - Setembro de 1993.

TERRA, N. N.; TERRA, A. B. de M.; TERRA, L. de M., Defeitos nos Produtos Cárneos: origens e soluções, São Paulo - SP 2004, Editora Varela.

TERRA, N., Particularidades na fabricação do salame, Revista Nacional da Carne, Ed. 317, Julho de 2003. Disponível em <http://www.dipemar.com.br/CARNE/317/materia_aditivos2_carne.htm>. Acesso em: 31 jan 2006.

TOWSEND, W. E.; BARD, J. CURED MEATS. In: Price B. S.; Schweigert B.S. The Science of Meat and Meat Products. 2 a edição. San Francisco. W. H. Freeman and Company, 1971. p. 452-470. 
THRUN, D. Sistemática do gerenciamento do processo suportado em medidas de controle para os serviços internos para uma indústria de alimentos. Florianópolis, 2003119 p. Dissertação de Mestrado, Universidade Federal de Santa Catarina.

VIOTT, A.; STOLBERG, J.; PELIZER, M. R. Qualidade microbiológica e físicoquímica de salames tipo coloniais da região do Alto Uruguai Catarinense, Revista Higiene Alimentar, v. 20, nº 138, janeiro/fevereiro de 2006.

VIVAN, A. M.; BEZERRA, R. T.R. e FONSECA, C. A. C. Produtos de origem animal do tipo colonial $\mathbf{x}$ industrializados. Caderno de Pesquisas em Administração, São Paulo, v. 09, nº 2, abril/junho 2002.

http://www.agricultura.gov.br/portal/page?_pageid=33,961080\&_dad=portal\&_schem a=PORTAL - Acesso em: jan. 2007. 


\section{ANEXOS}

\section{ANEXO A - PROCESSO DE DEFUMAÇÃO DO SALAME FINO}

$\underline{\text { Ingredientes }}$

- 650 gramas de carne suína

- 200 gramas de carne bovina magra

-150 gramas de toucinho firme (da região lombo-costal)

-tripa reta bovina, garganta ou tripa artificial

\section{Para o tempero}

-30 gramas de sal

$-2,5 \mathrm{Kg}$ de glucose (karo)

-2,5 Kg de açúcar

$-2,5 \mathrm{Kg}$ de cura (sal que se vende em açougue)

-2,0 Kg de pimenta branca moída

- 2,0 gramas de alho moído 
$-0,2$ de noz-moscada

-2,5 g de fixador ou ácido ascórbico

$-5 \mathrm{ml}$ de vinho tinto seco - opcional

\section{$\underline{\text { Produção }}$}

Depois de desossada e cortada em tiras, moa a carne bovina em chapa fina, de 5 milímetros ou menor, e a carne suína em chapa de 12 milímetros. Pique o toucinho em pequenos cubos (no menor tamanho possível) e vá adicionando os ingredientes à massa de carne na proporção citada, misturando bem. Não se esqueça de deixar o ácido ascórbico ou o fixador, que reduzem a acidez da carne, por último. Misture bem até dar liga momento em que a carne começa a grudar na mão. Deixe repousar por três horas antes de embutir. Se a carne for fresca, recomendase deixar em repouso de um dia para outro para escorrer a água em excesso.

Depois de terminar de embutir, deixe descansar e secar por algumas horas. Pode-se inclusive deixar no defumador aberto a $30^{\circ} \mathrm{C}$ de um dia para outro. Depois disso, defume a uma temperatura de 30 a $35^{\circ} \mathrm{C}$ por 24 horas. 


\section{ANEXO B - INFORMAÇÕES ADICIONAIS DA PRODUÇÃO DO SALAME}

- Formulações com $4 \%$ de Cloreto de sódio podem favorecer o desenvolvimento de Staphylococcus coagulase positiva;

- Quantidades de açúcar superiores a 2\% reduzem a velocidade de fermentação devido à ocupação de parte da água disponível;

- Temperaturas baixas, por ocasião da fermentação, auxiliam no controle dos microrganismos patogênicos;

- A defumação dificulta o processo fermentativo;

- Quedas rápidas de pH poderão conduzir à não-suficiente redução do nitrato a nitrito, deixando no salame um residual muito alto de nitrato, aumentando as chances de formação de nitrosaminas, que são compostos cancerígenos;

- As culturas iniciadoras (Starter), ao reduzirem o residual de nitrito, diminuem a possibilidade da formação de nitrosaminas; 
- A adição de magnésio ou de manganês (1ppm) reduz o tempo de fabricação do salame;

- A velocidade do ar na câmara climatizada, sob hipótese alguma, poderá ser superior a $0,5 \mathrm{~m} /$ segundo;

- A adição de proteínas do leite ao salame reduz a quebra de peso do mesmo;

- O desenvolvimento de mofos superficiais por ocasião da fabricação do salame é mais um fator de qualidade, pois auxilia no controle da rancificação;

- Jamais deixar no local de produção as peças de salame com baixas temperaturas, pois as mesmas irão condensar a umidade;

- Ao moer as carnes e o toicinho, utilizar facas bem afiadas, tendo em vista a necessidade do corte ser nítido. 


\section{ANEXO C - PONTOS CRÍTICOS DA FABRICAÇÃO DE SALAME}

\begin{tabular}{ll}
\hline PONTOS CRITICOS & BPF E VALORES \\
\hline Carga microbiana das carnes & Contagem de microrganismos aeróbios não \\
& $\begin{array}{l}\text { deve exceder a } 5 \times 10^{6} \text { ufc/g. } \\
\text { Enterobacteriaceae não deve exceder a } 10^{5} \\
\text { ufc/g. }\end{array}$ \\
\hline
\end{tabular}


Temperatura das carnes

$\mathrm{pH}$ das carnes

Adição de nitrito

Adição de nitrato

Aw das carnes

Adição de açúcar

Adição de glucono-delta-lactona

Adição de cultura starter

Temperatura de fermentação

Umidade relativa do ar

Velocidade do ar

Microflora interna do embutido

\section{Microrganismos superficiais desejáveis}

Microrganismos superficiais indesejáveis

Defumação

Valor de $\mathrm{pH}$

Aw do embutido
Armazenar as carnes em temperaturas ao redor de $0^{\circ} \mathrm{C}$ para evitar o crescimento de flora indesejável. Para evitar o crescimento da Salmonella nunca armazenar em temperaturas superiores a $7^{\circ} \mathrm{C}$.

Nunca usar carne com pH superior a 5,8

Aproximadamente $125 \mathrm{ppm}$

Aproximadamente $300 \mathrm{ppm}$

Não deve exceder a 0,96

Para produtos de lenta fermentação a adição de glicose/sacarose é de $0,3 \%$. Para produtos de rápida fermentação a adição é de $0,5 \%$ a $0,7 \%$. A lactose pode substituir a glicose/lactose em porcentagens de $0,5 \mathrm{e}$ $1,0 \%$ respectivamente.

Para produtos de rápida fermentação a adição é de $0,3 \%$.

Usar mistura de lactobcilos e micrococos

Não superior $22^{\circ} \mathrm{C}$ no início da fermentação. Quando usar nitrato, não superior a $18^{\circ} \mathrm{C}$ Iniciar a fermentação com $90 \%$ e reduzir gradualmente para $75 \%$

No início da fermentação usar de 0,8 a $0,5 \mathrm{~m} / \mathrm{s}$. Próximo do final da fermentação reduzir para 0,5 a $0,2 \mathrm{~m} / \mathrm{s}$.

No início com vários gêneros, porém no decorrer da fermentação passam a predominar as bactérias lácticas (Lactobacilus, Pediococcus, etc). Micrococus e leveduras são desejáveis. No final o embutido não deve contar mais de $10^{4} \mathrm{ufc} / \mathrm{g}$ de enterobacterias.

Mofos do gênero Penicilium ou leveduras do gênero Debaromyces.

Defumação leve previne o desenvolvimento de mofos, imersão em solução a 15 ou $20 \%$ de sorbato antes da armazenagem ou transporte é muito útil.

Depende do tipo de embutido. Não exceder a $1 \mathrm{ppm}$ de 3-4 benzeno-pireno.

Deve cair para 5,0 dentro do $2^{\circ}$ dia (fermentação rápida) ou 4 a 6 dias na fermentação normal. Baixas temperaturas $\left(<18^{\circ} \mathrm{C}\right)$ fornecem menos acidificação. Em fermentação rápida é $<0,95$. Em fermentação longa é de $<0,90$. Para exportar para os EUA ou Japão deve ser igual ou $<0,86$. 